\title{
Impaired Knowledge of Driving Laws Is Associated with Recommended Driving Cessation in Cognitively Impaired Older Adults
}

\author{
Michael L. Alosco ${ }^{a} \quad$ Brian R. Ott $^{b} \quad$ Mary Jo Cleveland ${ }^{c} \quad K^{2}$ risty Royle ${ }^{c}$ \\ Stephanie Snyder ${ }^{c}$ Mary Beth Spitznagel ${ }^{a} \quad$ John Gunstad ${ }^{a}$ \\ ${ }^{a}$ Department of Psychology, Kent State University, Kent, Ohio, ${ }^{b}$ Alzheimer's Disease and Memory \\ Disorders Center, Rhode Island Hospital, Warren Alpert Medical School of Brown University, \\ Providence, R.I., and ${ }^{\mathrm{C} C e n t e r}$ for Senior Health, Summa Health System, Akron, Ohio, USA
}

\section{Key Words}

Cognitive impairment $\cdot$ Driving performance $\cdot$ Driving license $\cdot$ Road traffic $\cdot$ Knowledge of driving laws

\begin{abstract}
Background/Aims: The present study examined if knowledge of driving laws independently predicts on-the-road driving performance among cognitively impaired older adults. Methods: The current study consisted of retrospective observational analyses on 55 cognitively impaired older adults (77.9 \pm 6.4 years) that completed an on-the-road driving evaluation, a 20 -item knowledge test of driving laws, and a brief cognitive test battery. Results: Logistic regression found poorer performance on the knowledge test was significantly associated with greater likelihood of recommended driving cessation beyond important demographic and cognitive variables $(p<0.05)$. Conclusion: Cognitively impaired patients' ability to drive may be related to their knowledge regarding common driving laws, in addition to their current level of cognitive functioning.

Copyright $\odot 2011$ S. Karger AG, Basel
\end{abstract}

\section{Introduction}

With the increasing age of the American population, the number of licensed drivers with cognitive impairment is likely to rise $[1,2]$. Drivers with dementia pose a serious risk of harm to themselves and others, with an elevated risk of crashing relative to non-demented coun- 
terparts [3]. However, despite these risks, persons with dementia often continue to drive [4, 5]. As such, to maintain the safety of the road, most countries have initiated procedures to identify factors that increase accident risk and driving impairment among persons with dementia [6].

Past work has identified a growing number of demographic and psychosocial predictors of driving cessation and driving impairment a mong older adults with cognitive impairment, including advancing age, urban living, lower income, less education, and increased number of medical conditions [7-14]. Furthermore, several studies have found lower scores on the Mini Mental State Examination [7, 15], and deficits in visuo-attentional and executive function are associated with poorer driving performance [16, 17].

There is reason to believe that a patient's knowledge of common driving laws may also influence driving performance. For example, past work has shown drivers with dementia perform significantly worse on a traffic sign recognition task than healthy older drivers [18, 19]. Additionally, persons with dementia performed worse on a written knowledge test of driving laws than healthy controls independent of their level of cognitive impairment [20]. Such findings suggest that direct assessment of driving knowledge among patients with dementia may provide useful information when evaluating driving fitness, though no study has examined whether knowledge of driving laws corresponds to on-the-road performance in cognitively impaired older persons. The purpose of the current study was to examine whether patients' knowledge of driving laws independently predicts expert-recommended driving cessation based upon an on-the-road assessment. We hypothesized that poorer performance on the written knowledge test would be associated with increased likelihood of recommendation to discontinue driving. Follow-up analyses were then performed to determine cognitive, medical and demographic differences between patients who were and were not advised to discontinue driving.

\section{Methods}

\section{Participants}

The current analyses consisted of 55 persons from the Center for Senior Health at Summa Health System in Akron, Ohio, USA, referred for an on-the-road driving evaluation. Based upon a comprehensive geriatrician evaluation, all participants had a working diagnosis of dementia or mild cognitive impairment (MCI). Participants of the current study reflect the dementia population receiving evaluation and treatment at that facility. Based upon geriatrician evaluation and reported family concerns, patients were initially referred to a licensed occupational therapy (OT) for assessment of their instrumental activities of daily living at this facility. Based upon the OT assessment, patients were then referred for an onthe-road driving evaluation at a professional driving school. Retrospective observational analyses were conducted on 55 consecutive cases that were referred and completed the onthe-road evaluation.

Participants were $77.9 \pm 6.4$ years of age (mean $\pm \mathrm{SD}$ ), and $45.5 \%$ were female. Within the sample, $43.7 \%$ had a working diagnosis of Alzheimer's disease, $21.8 \%$ dementia not otherwise specified, $16.4 \%$ vascular dementia, $10.9 \%$ mild cognitive impairment, $5.4 \%$ either Parkinson's disease or frontal lobe dementia, and $1.8 \%$ mixed dementia (see table 1 for participant demographic and medical characteristics).

\section{Procedures}

Patients were referred to the Center for Senior Health at Summa Health System for cognitive and memory complaints. Based on a routine geriatrician evaluation and presenting 
Table 1. Demographic, clinical, and driving characteristics of 55 cognitively impaired older adults

$\begin{array}{lc}\text { Demographic characteristics } & \\ \text { Age, years }^{1} & 77.85 \pm 6.39 \\ \text { Female, \% }^{1} & 45.5 \\ \text { Education, years }^{1} & 13.41 \pm 2.75 \\ \text { Medical characteristics, \% yes }^{\text {Hypertension }} & 67.3 \\ \text { Cholesterol } & 52.7 \\ \text { Diabetes } & 23.6 \\ \text { Stroke } & 18.2 \\ \text { Sleep apnea } & 9.1 \\ \text { CABG/bypass surgery } & 12.7 \\ \text { Test performance } & \\ \text { SBT } & 7.85 \pm 5.78 \\ \text { CDT } & 4.82 \pm 1.63 \\ \quad \text { Rules of the road } & 88.82 \pm 8.44 \\ \text { Driving cessation, \% yes } & \\ \quad \text { On-road recommendation } & 34.5\end{array}$

$\mathrm{CABG}=$ Coronary artery bypass graft. ${ }^{1}$ Mean $\pm \mathrm{SD}$

complaints of the family, patients were then referred and completed an OT assessment. As part of the assessment, patients were administered cognitive tests, including the Short Blessed Test (SBT) and the Clock-Drawing Test (CDT). Based on the results of this assessment, the licensed OT then referred the patient for an on-the-road assessment to be conducted at a professional driving school by a certified driving rehabilitation specialist. Driving recommendations made by the certified driving rehabilitation specialist (i.e., continue or discontinue driving) were used in the current analyses.

\section{Measures}

Knowledge Test

A knowledge test of common driving laws was created by licensed occupational therapists and consists of 20 multiple-choice questions abstracted from the manual of the Ohio Bureau of Motor Vehicle rules. Examples of questions include, 'Unless it is posted otherwise, the speed limit in a residential area is...?'; 'The speed limit in a school zone is...?' For each question, the patient is asked to select from four options. The test concludes with pictures of five road signs and the patient is asked to identify the meaning of each sign. Examples of signs include a yield sign, no parking sign, left turn only sign, no U-turn sign, and a pedestrian walking sign. Percent correct is used as the dependent variable. The internal consistency reliability of this measure was Cronbach's $\alpha=0.36$. Decreased internal consistency reliability is consistent with other measures of driving law knowledge [20].

\section{Cognitive Measures}

Short Blessed Test. The SBT is a very brief, 6-item, screening tool used to diagnose cognitive impairment [21]. It was used to assess orientation, memory, and concentration. Patients are asked to report the current year, month, time of day, count backward from 20 to 1 , recite the months backwards, and memorize a phrase [22]. Higher scores indicate poorer performance with scores of $0-4$ representing normal cognition, 5-9 reflective of questionable impairment or early dementia, and scores $\geq 10$ indicative of dementia [22]. 
Clock-Drawing Test. The CDT was used to assess deficits in visuospatial and executive function. It is a valuable screening tool commonly used to detect visual-spatial dysfunction among patients with dementia [23]. It was scored on a scale of 1-7, with higher scores representing better performance. This test demonstrates strong specificity among dementia patients in both in- and outpatient settings, as it has been shown to correctly classify $77 \%$ of patients with Alzheimer's disease, $89 \%$ of patients with mixed dementia, and $78 \%$ of normal elderly in these settings [24].

Demographic and Medical History

Demographic characteristics and medical history were collected through a review of the medical charts (table 1).

\section{Statistical Analyses}

A hierarchical binary logistic regression was performed to examine the independent contribution of the knowledge test on recommendations for driving cessation $(1=$ yes; $0=$ no) among the current sample of older adults with cognitive impairment. Age, gender, and education were controlled for and entered into the first block of the model. Cognitive predictors, namely the SBT and the CDT, were entered into the second block of the model. The knowledge test was entered into the third block of the model to determine its incremental predictive validity over cognitive and demographic variables. $\chi^{2}$ and independent-sample $t$ tests then determined cognitive, medical and demographic differences between patients who were and were not advised to discontinue driving.

\section{Results}

Cognitive and Driving Characteristics of the Sample

Consistent with their diagnoses, participants exhibited significant levels of cognitive impairment on testing. The average SBT score was $7.85 \pm 5.79$ [22]. Within the sample, $38.2 \%$ scored $0-4$ points on the SBT, $18.2 \%$ scored $5-9$ and $43.7 \%$ had a score $\geq 10$. Recommendation for driving cessation was common in the current sample $(34.5 \%$; 19 of 55 patients). The sample averaged $88.82 \%$ on the knowledge test.

\section{Medical, Demographic, and Cognitive Differences}

$\chi^{2}$ statistics were conducted to identify medical and demographic differences between patients who were and were not advised to discontinue driving based on their performance during the on-the-road assessment. There were no significant differences between males and females $\left[\chi^{2}(1, \mathrm{n}=55)=1.81, \mathrm{p}=0.18\right]$. Similarly, there were no differences between patients on any of the medical variables, namely: hypertension $\left[\chi^{2}(1, n=55)=0.22, p=0.64\right]$, coronary artery bypass graft surgery $\left[\chi^{2}(1, \mathrm{n}=55)=0.13, \mathrm{p}=0.72\right]$, cholesterol $\left[\chi^{2}(1, \mathrm{n}=55)=\right.$ $0.00, \mathrm{p}=0.99]$, diabetes $\left[\chi^{2}(1, \mathrm{n}=55)=2.76, \mathrm{p}=0.10\right]$, stroke $\left[\chi^{2}(1, \mathrm{n}=55)=0.11, \mathrm{p}=0.74\right]$, or sleep apnea $\left[\chi^{2}(1, \mathrm{n}=55)=0.52, \mathrm{p}=0.47\right]$.

Independent-sample $t$ tests were then performed to examine differences on the cognitive tests and the knowledge test between patients advised or not advised to discontinue driving based upon the on-the-road assessment. The t-tests revealed significant differences on the SBT $[t(53)=2.28, p<0.05]$ and on the knowledge test $[\mathrm{t}(53)=-4.11, \mathrm{p}<0.05]$. In each case, persons with poorer test scores were more likely to be advised to discontinue driving. No such pattern emerged on the CDT $[\mathrm{t}(53)=-0.79, \mathrm{p}>0.05]$. 
Table 2. Logistic regression analysis examining the predictive validity of the knowledge test on driving cessation among 55 cognitively impaired older adults (full model)

\begin{tabular}{|c|c|c|c|c|c|c|}
\hline Predictors & B & SE B & Wald's $\chi^{2}$ & d.f. & $\mathrm{p}$ & $e^{B}$ \\
\hline Constant & -2.91 & 7.46 & 0.15 & 1 & 0.69 & 0.06 \\
\hline Age & 0.15 & 0.07 & 4.80 & 1 & 0.03 & 1.11 \\
\hline Gender & -1.62 & 0.89 & 3.29 & 1 & 0.07 & 0.20 \\
\hline Education & 0.17 & 0.16 & 1.09 & 1 & 0.30 & 1.19 \\
\hline SBT & 0.12 & 0.08 & 2.64 & 1 & 0.10 & 1.13 \\
\hline CDT & -0.18 & 0.26 & 0.48 & 1 & 0.49 & 0.83 \\
\hline Knowledge test & -0.13 & 0.05 & 7.20 & 1 & 0.01 & 0.88 \\
\hline Test & & & $\chi^{2}$ & d.f. & $\mathrm{p}$ & \\
\hline \multicolumn{7}{|l|}{ Overall model } \\
\hline Likelihood ratio test & & & 24.14 & 6 & 0.00 & \\
\hline \multicolumn{7}{|l|}{ Goodness-of-fit test } \\
\hline Hosmer \& Lemeshow & & & 10.11 & 7 & 0.18 & \\
\hline
\end{tabular}

Nagelkerke $\mathrm{R}^{2}=0.49$.

Knowledge of the Rules of the Road Is an Independent Predictor of Driving Cessation

Finally, a hierarchical binary logistic regression was performed to identify the predictive validity of the knowledge test on driving cessation (yes or no). Age, gender ( $1=$ males; $0=$ females), and education were entered into the first block of the model. A test of this model against the constant was not statistically significant $\left[\chi^{2}(3)=5.86, p>0.05\right]$.

The SBT and the CDT were then entered into the second block of the model. After controlling for age, gender, and education, this block was statistically significant $\left[\chi^{2}(2)=9.29\right.$, $\mathrm{p}<0.05$; Nagelkerke $\mathrm{R}^{2}=0.33$ ]. The model correctly classified $69.1 \%$ of the cases. The Wald criterion demonstrated that age made a significant contribution to the prediction $[B=0.15$, odds ratio $\left.(\mathrm{OR})=1.16, \chi^{2}(1)=5.63, \mathrm{p}<0.05\right]$, as did gender $\left[\mathrm{B}=-1.75, \mathrm{OR}=0.17, \chi^{2}(1)=\right.$ $4.79, \mathrm{p}<0.05]$, and the SBT $\left[\mathrm{B}=0.17, \mathrm{OR}=1.18, \chi^{2}(1)=5.84, \mathrm{p}<0.05\right]$. Older age, being female, and worse performance on the SBT was associated with increased odds of being advised to discontinue driving.

The knowledge test was then entered into the final block of the model. After controlling for the demographic, and cognitive variables, this block was statistically significant $\left[\chi^{2}(1)=\right.$ $9.00, \mathrm{p}<0.01]$, as was the full model $\left[\chi^{2}(6)=24.14, \mathrm{p}<0.01\right.$, Nagelkerke $\mathrm{R}^{2}=0.49$ ]. The full model correctly classified $78.2 \%$ of the cases. The Wald criterion demonstrated that age made a significant contribution to the prediction $\left[\mathrm{B}=0.15, \mathrm{OR}=1.17, \chi^{2}(1)=4.80, \mathrm{p}<0.05\right]$, as did the knowledge test $\left[\mathrm{B}=-0.13, \mathrm{OR}=0.88, \chi^{2}(1)=7.20, \mathrm{p}<0.05\right]$. Older age and worse performance on the knowledge test were associated with increased odds of recommendation to discontinue driving (table 2 for a summary of the full model).

\section{Discussion}

Consistent with past work, recommended driving cessation was common among cognitively impaired older adults who were referred due to concerns by a geriatrician and occupational therapist. Previous work has identified a growing number of predictors of driving ability in this population, including severity of cognitive impairment. The current study ex- 
tends the literature by demonstrating that knowledge of driving laws, independent of cognitive function and demographic variables, is also associated with recommended driving cessation after an on-the-road evaluation. The implications of these findings warrant brief discussion.

The current findings demonstrate that poorer performance on a knowledge test of common driving laws was associated with increased odds of being advised to discontinue driving in persons with cognitive impairment. Prior work has shown that dementia patients consistently perform worse on knowledge tests than healthy elderly [18-20, 25]. However, this is the first study to show that knowledge of driving laws is associated with poorer on-the-road performance independent of cognitive ability. Interestingly, a past study found nearly $25 \%$ of healthy controls failed a written test of driving laws, suggesting that even healthy older drivers may be at risk for reduced knowledge and potentially reduced driving performance [20]. When drivers reach a certain age in the United States, shortened valid licensing periods [26, 27], in-person renewals, and vision tests are required [28]. Written knowledge tests are not yet routine and are often only administered in specific circumstances (i.e., post-traffic violations or medical reports) [26, 29]. In fact, some states administer knowledge tests as a means to help identify impaired reading, comprehension, or perceptual skills, and knowledge of driving laws is often a secondary concern [30]. However, previous work suggests that knowledge of driving laws deserves attention, as one study found a trend between knowledge tests and reduction in fatal crash risk among a healthy elderly community sample [31]. Future research examining the benefits of a knowledge test in predicting on-the-road performance in other samples would help validate its clinical utility for identifying at-risk drivers with cognitive impairment.

Consistent with past work, the current findings demonstrate that cognitive function was an important contributor to driving performance. Research has shown neuropsychological tests assessing attention, visual scanning, processing speed, visuospatial abilities, and executive function [32-34] predict on-the-road test performance in patients with dementia [35, 36]. Our study suggests that global cognitive screening measures may also have clinical utility in the assessment of driving fitness, though past findings are inconsistent $[37,38]$ and prospective studies examining the utility of such screening measures on driving performance are needed.

Limitations of the current findings deserve mention. First, the current study cannot provide mechanistic explanations for the association between written testing of driving laws and poorer driving performance in persons with cognitive impairment. Additionally, the current study utilized cross-sectional data, and prospective studies are needed to determine whether cognitive tests and knowledge of driving laws predict driving cessation over time, particularly in transitioning from healthy to pathological cognitive aging. Future studies should also examine driving cessation rates and predictors of driving cessation in other medical populations (i.e., cardiovascular disease or other chronic illness) to determine whether cognitive impairment and driving knowledge in those populations are both associated with poor driving performance. Finally, the current study lacks detailed quantification and assessment of past driving experiences, including history of crashes or near-crash incidents, so the implications of impaired knowledge in terms of driving safety remain to be elucidated.

A final aspect of the study warranting brief discussion is the measure of driving laws. Consistent with past studies [20], our driving knowledge measure exhibited low levels of internal consistency. Past researchers have speculated that the primary reason for the low internal consistency of similar measures is a result of decreased reliability of the actual state driving examinations from which the items were pooled [20]. Since the current knowledge test consisted of only 20 items drawn from a larger Bureau of Motor Vehicle manual commonly used to assess driving knowledge, a larger item sample would increase the internal consistency of this measure. Prospective studies utilizing comprehensive examinations of 
patients' knowledge of driving laws would help validate our findings; however, more intensive knowledge tests may not be practical for everyday clinical use.

In summary, poorer knowledge of driving laws was independently associated with the recommendation to discontinue driving in patients with dementia and mild cognitive impairment. Future studies should examine the benefits of adding evaluation of knowledge of common driving laws to screening evaluations of older drivers who may be at risk due to cognitive impairment.

\section{Acknowledgments}

Indirect support for the preparation of this study was obtained from DK075119, HL089311, and AG016335.

\section{Disclosure Statement}

There is no conflict of interest.

\section{References}

1 National Research Council: Committee for the Study on Improving Mobility and Safety for Older Persons: Transportation in an Aging Society. Washington, Transportation Research Board, 1994.

-2 Brown LB, Ott BR: Driving and dementia: a review of the literature. J Geriatr Psychiatry Neurol 2004; 17:232-240.

-3 Retchin SM, Hillner BE: The costs and benefits of a screening program to detect dementia in older drivers. Med Decis Making 1994;14:315-324.

-4 Lafont S, Laumon B, Helmer C, Dartigues JF, Gabrigoule C: Driving cessation and self-reported car crashes in older drivers: the impact of cognitive impairment and dementia in a population-based study. J Geriatr Psychiatry Neurol 2008;21:171-182.

-5 O'Neill D, Neubauer K, Boyle M, Gerrard J, Surmon D, Wilcok GK: Dementia and driving. J R Soc Med 1992;85:199-202.

6 Organisation for Economic Co-Operation and Development (OECD): Ageing and Transport: Mobility Needs and Safety Issues. Paris, OECD, 2001, p 11.

7 Adler G, Kuskowski M: Driving cessation in older men with dementia. Alzheimer Dis Assoc Disord 2003;17:68-71.

-8 Talbot A, Bruce I, Cunninghma CJ, Coen RF, Lawlor BA, Coakley D, Walsh JB, O’Neill D: Driving cessation in patients attending a memory clinic. Age Ageing 2005;34:363-368.

-9 Campbell MK, Bush TL, Hale WE: Medical conditions associated with driving cessation in community-dwelling, ambulatory elders. J Gerontol 1993;48:S230-S234.

-10 Dellinger AM, Sehgal M, Sleet DA, Barrett-Connor E: Driving cessation: what older former drivers tell us. J Am Geriatr Soc 2001;49:431-435.

-11 Jette AM, Branch LG: A ten-year follow up of driving patterns among the community dwelling elderly. Hum Factors 1992;34:25-31.

-12 Marottoli RA, Ostfeld AM, Merrill SS, Perlman GD, Foley DJ, Cooney LM: Driving cessation and changes in mileage driven among elderly individuals. J Gerontol 1993;48:S255-S260.

-13 O’Neill D, Bruce I, Kirby M, Lawlor B: Older drivers, driving practices and health issues. Clin Gerontol 2000;22:47-55.

-14 Chipman ML, Payne J, McDonough P: To drive or not to drive: the influence of social factors on the decisions of elderly drivers. Accid Anal Prev 1998;30:299-304. 
15 Herrmann N, Rapoport MJ, Sambrook R, Hebert R, McCracken P, Robillard A, Canadian Outcomes Study in Dementia (COSID) Investigators: Predictors of driving cessation in mild-to-moderate dementia. CMAJ 2006;12:591-595.

-16 Owsley C, Ball K, McGwin G Jr, Sloane ME, Roenker DL, White MF, Overley ET: Visual processing impairment and risk of motor vehicle crash among older adults. JAMA 1998;279:1083-1088.

-17 Daigneault G, Joly P, Frigon JY: Executive functions in the evaluation of accident risk of older drivers. J Clin Exp Neuropsychol 2002;24:221-238.

-18 Brashear A, Unverzagt FW, Kuhn ER, Glazier BS, Farlow MR, Perkins AJ, Hui SL: Impaired traffic sign recognition in drivers with dementia. Am J Alzheimers Dis Other Demen 1998;13:131-137.

-19 Carr DB, LaBarge E, Dunnigan K, Storandt M: Differentiating drivers with dementia of the Alzheimer type from healthy older persons with a traffic sign naming test. J Gerontol A Biol Sci Med Sci 1998;53:M135-M139.

-20 Adler G, Rottunda S, Christensen K, Kuskowski M, Thuras P: Driving SAFE: development of a knowledge test for drivers with dementia. Dementia 2006;5:213-222.

- 21 Katzman R, Brown T, Fuld P, Peck A, Schechter R, Schimmel H: Validation of a short orientationmemory-concentration test of cognitive impairment. Am J Psychiatry 1983;140:734-739.

-22 Morris JC, Heyman A, Mohs RC, Hughes JP, van Belle G, Fillenbaum G, Mellits ED, Clark C: The Consortium to Establish a Registry for Alzheimer's Disease (CERAD). Part I. Clinical and neuropsychological assessment of Alzheimer's disease. Neurology 1989;39:1159-1165.

-23 Lee H, Lawlor BA: State-dependent nature of the clock drawing task in geriatric depression. J Am Geriatr Soc 1995;43:796-798.

-24 Mangos PJ, Wu R: The ten point clock test: a quick screen and grading method for cognitive impairment in medical and surgical patients. Int J Psychiatry Med 1994;24:229-244.

-25 Uc EY, Rizzo M, Anderson SW, Shi Q, Dawson JD: Driver landmark and traffic sign identification in early Alzheimer's disease. J Neurol Neurosurg Psychiatry 2005;76:764-768.

26 Coley M: Older driver relicensing laws: the state of the states. Public Policy Aging Rep 2001;4:3-10.

-27 Stamatiadis N, Agent KR, Ridgeway M: Driver license renewal for the elderly: a case study. J Appl Gerontol 2003;22:42-56.

28 Cobb RW, Coughlin JF: Regulating older drivers: how are the states coping? J Aging Soc Policy 1997; 9:71-87.

29 National Highway Traffic Safety Administration: Model driver screening and evaluation program: final technical report www.nhtsa.dot.gov/people/injury/olddrive/modeldriver/3_app_b.htm, updated 2001 (accessed August, 24, 2011).

30 California Department of Motor Vehicles. Dementia. Sacramento, Department of Motor Vehicles, 2011, updated 2011, http://dmv.ca.gov/dl/driversafety/dementia.htm.

-31 Levy DT, Vernick JS, Howard KA: Relationship between drivers license renewal policies and fatal crashes involving drivers 70 years or older. JAMA1995;274:1026-1030.

- 32 McKnight AJ, McKnight AS: Multivariate analysis of age-related driver ability and performance deficits. Accid Anal Prev 1999;31:445-454.

- 33 Petridou E, Moustaki M: Human factors in the causation of road traffic crashes. Eur J Epidemiol 2000;16:819-826.

-34 Reger MA, Welsh RK, Watson GS, Cholerton B, Baker LD, Craft S: The relationship between neuropsychological functioning and driving ability in dementia: a meta-analysis. Neuropsychology 2004; $18: 85-93$.

- 35 Dawson JD, Anderson SW, Uc EY, Dastrup E, Rizzo M: Predictors of driving safety in early Alzheimer disease. Neurology 2009;72:521-527.

-36 Ott BR, Festa EK, Amick MM, Grace J, Davis JD, Heindel WC: Computerized maze navigation and on-road performance by drivers with dementia. J Geriatr Psychiatry Neurol 2008;21:18-25.

- 37 Fox GK, Bowden SC, Bashford GM, Smith DS: Alzheimer's disease and driving: prediction and assessment of driving performance. J Am Geriatr Soc 1997;45:949-953.

- 38 Trobe JD, Waller PF, Cook-Flannagan CA, Teshima SM, Bieliauskas LA: Crashes and violations among drivers with Alzheimer's disease. Arch Neurol 1996;53:411-416. 